\title{
Effect of Various Electrolytes on Theophylline Loaded Sodium Alginate Beads Prepared by Ionic Cross Linking Technique
}

\section{Sheikh Tasnim J ahan ${ }^{1}$, Sams Mohammad Anowar Sadat ${ }^{1}$, Muhammad Rashedul Islam ${ }^{1}$, A.T.M. Zafrul Azam ${ }^{2}$ and J akir Ahmed Chowdhury ${ }^{1}$}

\author{
${ }^{1}$ Department of Pharmaceutical Technology, Faculty of Pharmacy, University of Dhaka, \\ Dhaka-1000, Bangladesh \\ ${ }^{2}$ Department of Pharmaceutical Chemistry, Faculty of Pharmacy, University of Dhaka, \\ Dhaka-1000, Bangladesh
}

\begin{abstract}
The purpose of the present research work was to prepare alginate beads containing water soluble drug theophylline using ionic cross linking technique, with electrolyte type and concentration as variables. In this study, the beads were characterized and evaluated in respect of their surface morphology, swelling index and in vitro kinetics. The comparative study among the three polyvalent cationic cross linking agents $\mathrm{CaCl}_{2}$, $\mathrm{BaCl}_{2}$ and $\mathrm{Al}_{2}\left(\mathrm{SO}_{4}\right)_{3}$ were investigated based on their cationic charges. Divalent cation, $\mathrm{Ca}^{2+}$ and $\mathrm{Ba}^{2+}$ containing beads showed simultaneous decrease in drug release with increasing electrolyte amount. In case of $\mathrm{Al}^{3+}$ -alginate beads, the delay in release was due to the ability of $\mathrm{Al}^{3+}$ to form three dimensional bonding structure with the sodium alginate inside the beads. As a result, swelling of beads is delayed leading to slow disintegration. Scanning electron microscope (SEM) photomicrographs revealed that with the increase in the electrolyte concentration the density of the cross link is also increased. When the electrolyte concentration is $5 \%$ then the beads surface is rough and rod shape drug is visible. But when the electrolyte concentration is increased from $10 \%$ to $15 \%$ the surface is comparatively smoother and both the swelling property and in vitro drug release are decreased. Most of the formulations followed Higuchi drug release model.
\end{abstract}

Key words: Beads, alginate, ionic cross-linking, swelling index, polyvalent cation.

\section{INTRODUCTION}

The use of bead systems for controlling the release of drugs has increasingly become important in the formulation of pharmaceuticals. Natural hydrophilic polymers, owing to their characteristic biocompatibility and biodegradability properties, are widely exploited in the pharmaceutical industry for the development of novel drug delivery systems. Among these polymers, alginate is one that has been widely used in numerous biomedical applications, processed in various dosage forms (e.g., tablets, capsules, beads, rafts, liquid suspensions), and used in sutures and dressing materials with characteristic features such as mucoadhesion, bioadhesion, and modifying drug release profile. Chemically, alginates

Correspondence to: Jakir Ahmed Chowdhury

Tel: +880-2-7219747; Fax: +880-2-8615583

E-mail: jakir@univdhaka.edu

Dhaka Univ. J. Pharm. Sci. 11(2): 181-189, 2012 (December) are linear, anionic block copolymer heteropolysaccharides consisting of monomers of (d-mannuronic acid) (M) and its C-5 epimer, (l-guluronic acid) (G), residues joined together by 1,4-glycosidic linkages. The carboxylic acid groups located on the polymer backbone has an ionic interaction with bivalent alkaline earth metals $\mathrm{Ca}^{2+}, \mathrm{Sr}^{2+}$, and $\mathrm{Ba}^{2+}$ or trivalent $\mathrm{Fe}^{3+}$ and $\mathrm{Al}^{3+}$. An intramolecular bonding forms between the carboxylic acid and these cations. Ultimately a simple, mild, aqueous-based gel is formed by the inonotropic gelling action. ${ }^{1-8}$

Theophylline was selected as a model drug for incorporation in electrolyte-alginate beads. Theophylline, an alkaloid found in leaves of Camelia sinensis is used clinically as a bronchodilator in the management of Chronic Obstructive Pulmonary Disease (COPD). ${ }^{9}$

Conventional dosage forms of theophylline are administered 3-4 times a day to avoid large 
fluctuations in plasma concentrations. It is rapidly absorbed and eliminated. These attributes make theophylline a good candidate for making sustained release dosage form. On the other hand, the sustained release dosage form of theophylline provides desirable serum concentrations for prolonged periods without frequent dosing thereby providing patient compliance. ${ }^{10}$

The aim of the study was to evaluate controlled release of theophylline following oral administration of alginate beads. The beads formulation was characterized in terms of surface morphology by scanning electron microscopy (SEM), swelling index and in vitro drug release studies.

\section{MATERIALS AND METHODS}

Theophylline anhydrous was received as a sample gift from Eskayef Bangladesh Ltd. Sodium alginate was obtained from BDH Chemicals Ltd. Calcium chloride, barium chloride and aluminium sulphate were purchased from Merck (India).

Formulation of alginate beads. The beads were prepared by ionic cross-linking technique using the formulations as shown in Table 1. The alginate solution was prepared by dissolving the polymer in distilled water using gentle heat and was

Table 1. Formulations of alginate beads with different concentrations of various electrolytes.

\begin{tabular}{lccl}
\hline $\begin{array}{l}\text { Batch } \\
\text { code }\end{array}$ & $\begin{array}{c}\text { Theophylline } \\
(\mathrm{gm})\end{array}$ & $\begin{array}{c}\text { Sodium alginate } \\
(\mathrm{gm})\end{array}$ & \multicolumn{1}{c}{$\begin{array}{c}\text { Electrolyte } \\
\text { solution }(\%)\end{array}$} \\
\hline 1 & 1 & 2 & $\mathrm{CaCl}_{2} 5 \%$ \\
2 & 1 & 2 & $\mathrm{CaCl}_{2} 10 \%$ \\
3 & 1 & 2 & $\mathrm{CaCl}_{2} 15 \%$ \\
4 & 1 & 2 & $\mathrm{BaCl}_{2} 5 \%$ \\
5 & 1 & 2 & $\mathrm{BaCl}_{2} 10 \%$ \\
6 & 1 & 2 & $\mathrm{BaCl}_{2} 15 \%$ \\
7 & 1 & 2 & $\mathrm{Al}_{2}\left(\mathrm{SO}_{4}\right)_{3} 5 \%$ \\
8 & 1 & 2 & $\mathrm{Al}_{2}\left(\mathrm{SO}_{4}\right)_{3} 10 \%$ \\
9 & 1 & 2 & $\mathrm{Al}_{2}\left(\mathrm{SO}_{4}\right)_{3} 15 \%$ \\
\hline
\end{tabular}

stirred magnetically. On complete solution, an accurate weight quantity of theophylline was added to acquire homogenous dispersion. The sodium alginate-drug dispersion was added drop wise via hypodermic needle into solution of cross-linking agents. The cross- linking agents used were calcium chloride, barium chloride and aluminium sulphate in $5 \%, 10 \%$ and $15 \%$ concentration.

The droplets from the dispersions instantaneously gelled upon contact with solution of cross linking agents. The gel bead changed into discrete Theophylline-alginate matrices within next 15 minutes. Then the beads were decanted, washed with distilled water, dried in air for 36-48 hr. ${ }^{11,12}$

Surface morphology. The surface morphology of the beads were investigated using scanning electron microscopy which was performed using Hitachi (Model: S-3400 N, Japan) scanning electron microscope having different magnifications. Prior to examination the beads were placed on carbon tape and then placed on a disk to examine the surface. The samples include beads prepared using various electrolytes.

Swelling study. The extent of swelling was measured in terms of \% weight gained by the beads. The swelling behaviors of all the formulations were studied. In this test $20 \mathrm{mg}$ of beads from each formulation was kept in petridish containing distilled water. At the end of 1 hour, the beads were withdrawn, soaked with tissue paper and weighed. Then for every 1 hour, weight of beads was noted and the process was continued till the end of 8 hours, $\%$ weight gain by the beads was calculated by the following formula. ${ }^{13}$

Swelling Index $\left.\left.(\mathrm{SI})=\left\{\mathrm{W}_{\mathrm{t}}-\mathrm{W}_{\mathrm{o}}\right\} / \mathrm{W}_{0}\right)\right] \times 100$

Here, $\mathrm{W}_{\mathrm{t}}=$ Mass of swollen beads at time $\mathrm{t}$

$$
\mathrm{W}_{\mathrm{O}}=\text { Mass of dry beads at } \mathrm{t}_{\mathrm{o}}
$$

In vitro dissolution testing. In vitro release studies of prepared beads were carried out using USP rotating basket method in $900 \mathrm{ml}$ of distilled water at $37 \pm 0.5^{\circ} \mathrm{C}$ and $100 \mathrm{rpm}$. Dissolution was carried out for a total period of 8 hour using distilled water as dissolution medium. At periodic time intervals, $5 \mathrm{ml}$ of sample was withdrawn, suitably diluted and absorbance was measured at $271 \mathrm{~nm} .5$ $\mathrm{ml}$ of fresh dissolution media was added each time to maintain the sink conditions. ${ }^{11}$

Kinetic models. The suitability of several equations that are reported in the literature to identify the mechanisms for the release of theophylline 
was tested with respect to the release data. The data were evaluated according to the following equations: ${ }^{14}$

Zero-order equation:

$\mathrm{Qt}_{\mathrm{t}}=\mathrm{K}_{0} \mathrm{t}$

Higuchi equation based on Fickian diffusion :

$\mathrm{Q}_{\mathrm{t}}=\mathrm{K}_{\mathrm{H}} \sqrt{\mathrm{t}}_{\mathrm{t}}$

Where, $\mathrm{Q}$ is the amount of drug release in time $\mathrm{t}$, $\mathrm{K}_{0}$, and $\mathrm{K}_{\mathrm{H}}$ are rate constants of zero order and Higuchi rate equations, respectively. ${ }^{15,16}$

Korsmeyer-Peppas model:

$$
\log (\mathrm{Mt} / \mathrm{Mf})=\log \mathrm{k}+\mathrm{nlog} \mathrm{l}
$$

Where, Mt is the amount of drug release at time $\mathrm{t}$; Mf is the amount of drug release after infinite time; $\mathrm{k}$ is a release rate constant incorporating structural and geometric characteristics of the dosage form; $\mathrm{n}$ is the diffusional exponent indicative of the mechanism of drug release. ${ }^{17,18}$

\section{RESULTS AND DISCUSSION}

Effect of various concentration of $\mathrm{CaCl}_{2}$ on surface morphology of theophylline beads. Formulation 1, 2 and 3 were prepared with theophylline - alginate in 1:2 ratios. and, the electrolyte concentrations $\left(\mathrm{CaCl}_{2}\right)$ were $5 \%, 10 \%$ and $15 \%$, respectively.

SEM images of the beads in Figure 1a, $1 \mathrm{~b}$ and $1 \mathrm{c}$ indicate that $\mathrm{F} 3$ formed smooth beads compared to F1 and F2. The surface of the particle is indicating poor drug-polymer bonding in the beads. Surface of F1 shows that drug was loosely bound with the polymer molecules (Figure 2a). Whereas, in F2 (Figure 2b) the surface indicates closely packed drug-polymer bonding. In F3 (Figure 2c) more tight and dense bonding is observed.

Effect of various concentration of $\mathrm{BaCl}_{2}$ on surface morphology of theophylline beads. Cross linking agents has effect on surface morphology of different formulations. Divalent $\mathrm{Ba}^{2+}$ has the largest size $\left(1.74 \mathrm{~A}^{0}\right)$ as compared to the other cations (1.14 $\mathrm{A}^{0}$ for $\mathrm{Ca}^{2+}$ and $0.68 \mathrm{~A}^{0}$ for $\mathrm{Al}^{3+}$ ), it is expected to form strong alginate microspheres and with smaller voids. SEM image of beads formulated with $5 \%$
$\mathrm{BaCl}_{2}$ is compared with beads formulated with $10 \%$ $\mathrm{BaCl}_{2}$ and $15 \% \mathrm{BaCl}_{2}$. In Figures 3 and 4 , the surface can be differentiated where the cross linking of alginate and divalent $\mathrm{Ba}^{2+}$ is increasing, which is visible. The rod shaped theophylline entrapped within the cross link is also visible. The rod shaped drug is visible at magnification of 1000 for $\mathrm{F} 4$ whereas, for formulation 5 and 6 the rod shaped theophylline within the cross link is clearly visible at only magnification of 500. So with the increase in electrolyte concentration, the density of the cross link is observed accordingly (Figure 3 and 4).

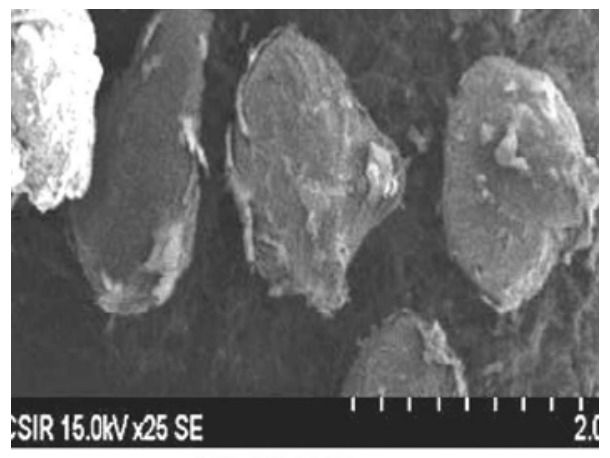

a) $\mathrm{F} 1: 5 \% \mathrm{CaCl}_{2}$

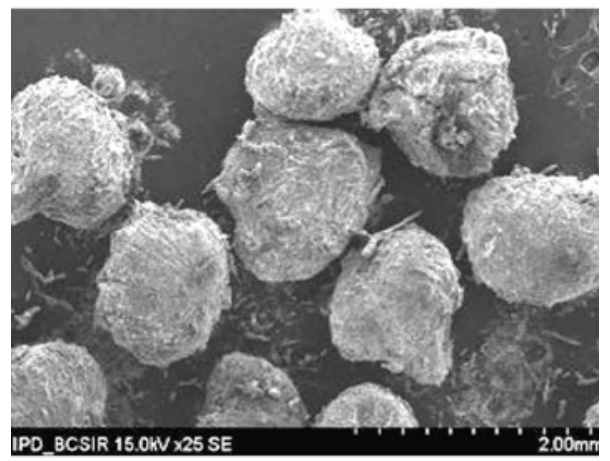

b) $\mathrm{F} 2: 10 \% \mathrm{CaCl}_{2}$

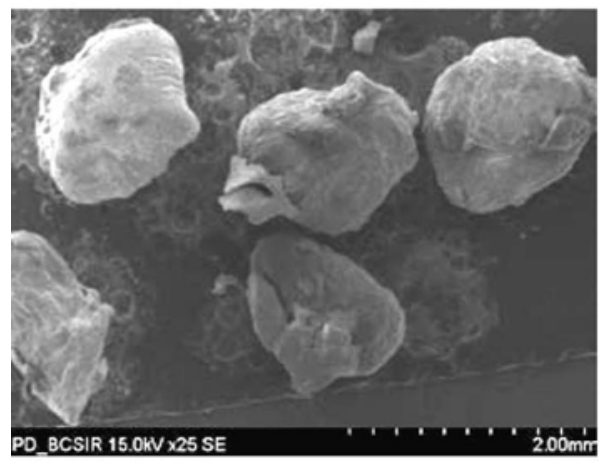

c) $\mathrm{F} 3: 15 \% \mathrm{CaCl}_{2}$

Figure 1. Scanning electron microscopic photomicrographs of F1, $\mathrm{F} 2$ and $\mathrm{F} 3$ at magnification $\times 25$ 


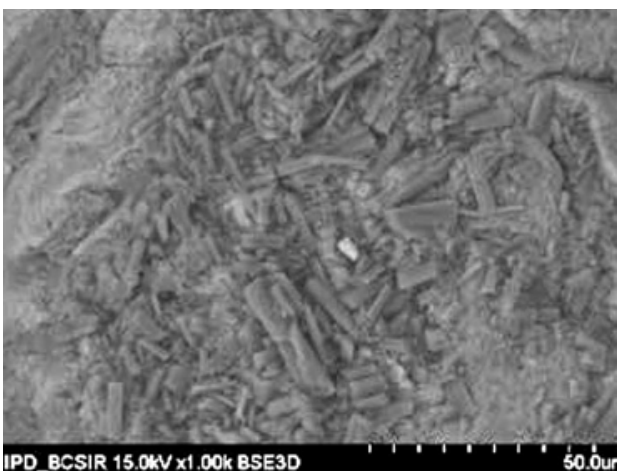

a) $\mathrm{F} 1: 5 \% \mathrm{CaCl}_{2}$

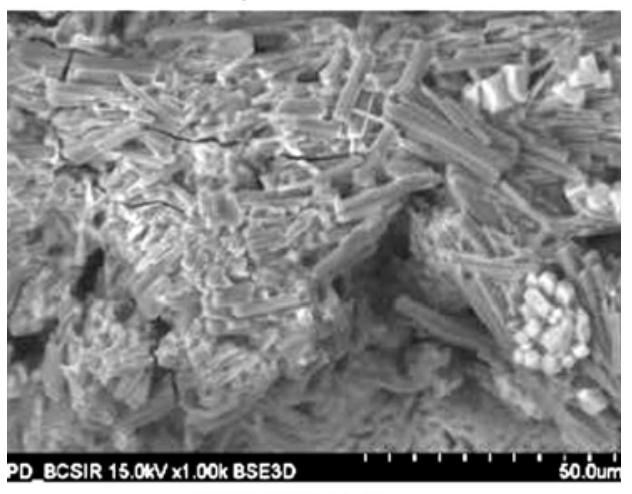

b) $\mathbf{F 2 : ~} 10 \% \mathrm{CaCl}_{2}$

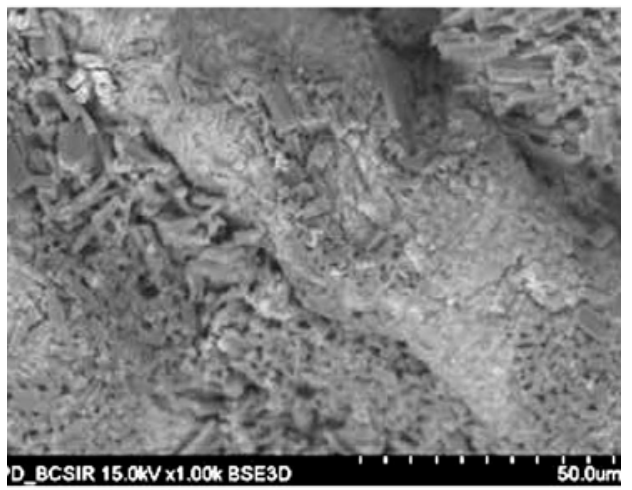

c) $\mathrm{F} 3: 15 \% \mathrm{CaCl}_{2}$

Figure 2. Scanning electron microscopy photomicrographs of F1, $\mathrm{F} 2$ and $\mathrm{F} 3$ at magnification $\times 1000$

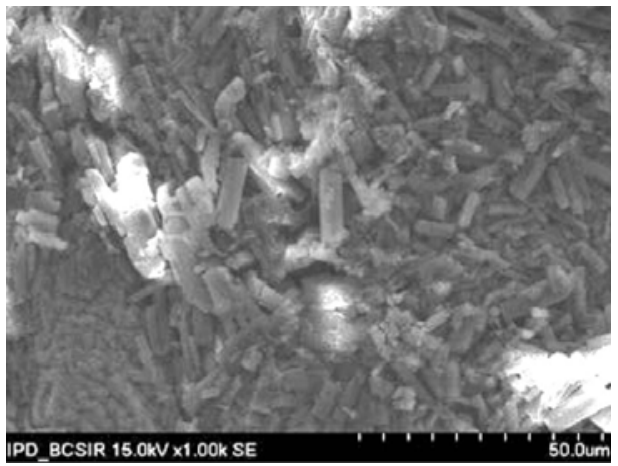

Figure 3. SEM of Formulation $4\left(5 \% \mathrm{BaCl}_{2}\right)$ at magnification $\times 1000$
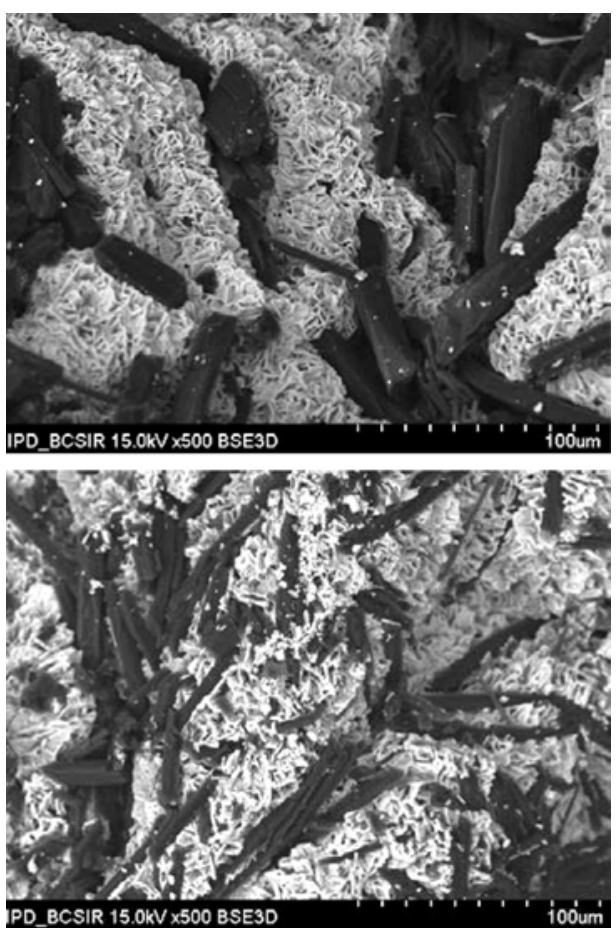

Figure 4. Scanning electron microscopy photomicrographs of F5 $\left(10 \% \mathrm{BaCl}_{2}\right)$ and $\mathrm{F} 6\left(15 \% \mathrm{BaCl}_{2}\right)$ at magnification $\times 500$

Effect of various concentration of $\mathrm{Al}_{2}\left(\mathrm{SO}_{4}\right)_{3}$ on surface morphology of theophylline beads. In formulation 7, 8 and 9 the beads are formed using trivalent cation $\mathrm{Al}^{3+}$, where cross linking occurs between $\mathrm{Al}^{3+}$ and alginate. These formulations contain 5, 10 and $15 \% \mathrm{Al}_{2}\left(\mathrm{SO}_{4}\right)_{3}$, respectively. This three dimensional bonding results in extended cross linking through the whole microsphere producing hard alginate microspheres.

In Figure $5 \mathrm{a}, 5 \mathrm{~b}$ and $5 \mathrm{c}$, the beads surface is observed. The surface of the beads was very rough, porous, and uneven surface was observed in case of all three formulations which were probably due to the uneven distribution of the drug particles throughout the whole bead surface. Surface morphology at magnification 500 reveals that there was cracks and pores on surface in case of formulation 7 and 8 (Figure 5a and 5b). In case of formulation 9, rod shaped theophylline was observed. Thus, when the electrolyte concentration is $15 \%$ the availability of aluminium for cross linking with sodium alginate is highest. In that case, more drug remains entrapped within the cross link which is the reason of visibility 
of rod shaped theophylline at magnification 500

(Figure 5c).

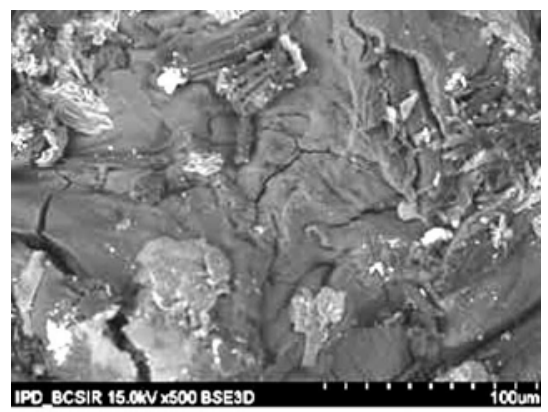

a) F7: $5 \% \mathrm{Al}_{2}\left(\mathrm{SO}_{4}\right)_{3}$

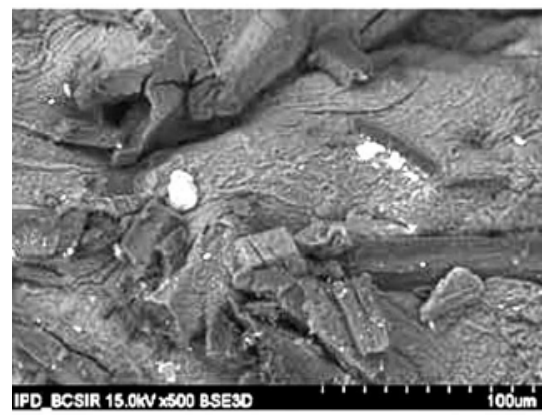

b) F8: $10 \% \mathrm{Al}_{2}\left(\mathrm{SO}_{4}\right)_{3}$

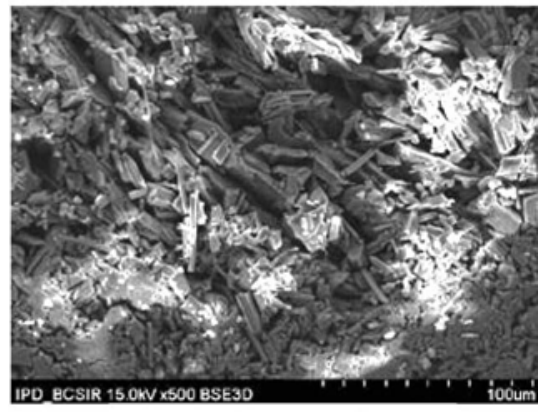

c) $\mathrm{F} 9: 15 \% \mathrm{Al}_{2}\left(\mathrm{SO}_{4}\right)_{3}$

Figure 5. Scanning electron microscopic photomicrographs of formulation 7,8 and 9 at magnification $\times 500$

\section{Swelling study:}

Effect of different concentration of $\mathrm{CaCl}_{2}$, $\mathrm{BaCl}_{2}$ and $\mathrm{Al}_{2}\left(\mathrm{SO}_{4}\right)_{3}$ solution on theophyllinealginate beads formulations. Swelling study on formulation F1, F2, F3 is done to observe the effect of electrolyte concentration. F1 (12.29\%) swelled high up to 5 hours. F2 (5.91\%) and F3 (5.09\%) swelled higher up to $4 \mathrm{hrs}$ and $3 \mathrm{hrs}$, respectively (Figure 6). Falamarzian and Varshosaz showed that Ca- alginate beads had a better swelling kinetic and wall strength. ${ }^{19}$ F4, F5, F6 contains $\mathrm{BaCl}_{2}$ solution of $5 \%, 10 \%, 15 \%$, respectively. Among them F8 swelled the highest i.e. $7.90 \%$ up to 5 hour. Whereas, F9 and F10 has SI of 7.58\% and 5.91\%, respectively (Figure 7). Swelling indices of alginate based theophylline beads with $\mathrm{Al}_{2}\left(\mathrm{SO}_{4}\right)_{3}$ as crosslinking agent was $8.09 \%$ at 5 hour, $5.49 \%$ at 4 hour and $4.47 \%$ at 3 hour for F7, F8 and F9, respectively (Figure 8).

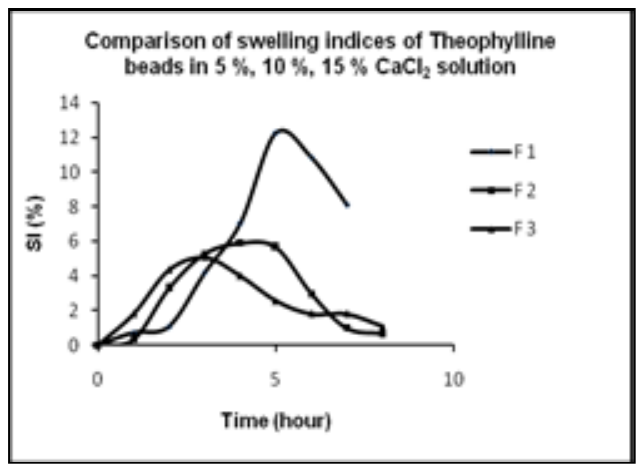

Figure 6. Comparison of swelling index of alginate based theophylline beads in $5 \%, 10 \% \& 15 \% \mathrm{CaCl}_{2}$ solution

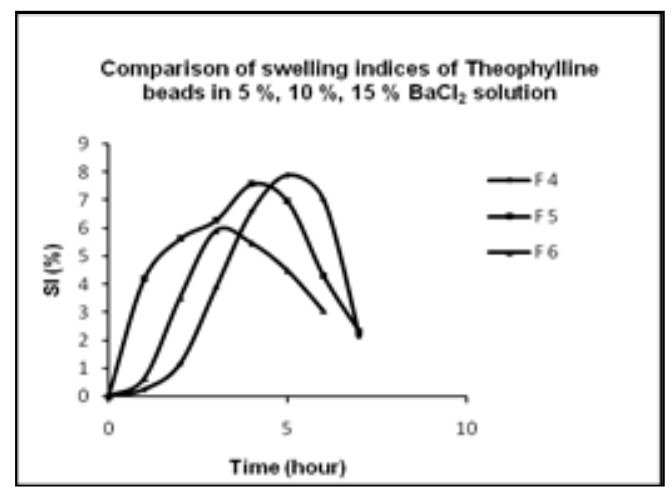

Figure 7. Comparison of swelling index of alginate based theophylline beads in $5 \%, 10 \% \& 15 \% \mathrm{BaCl}_{2}$ solution

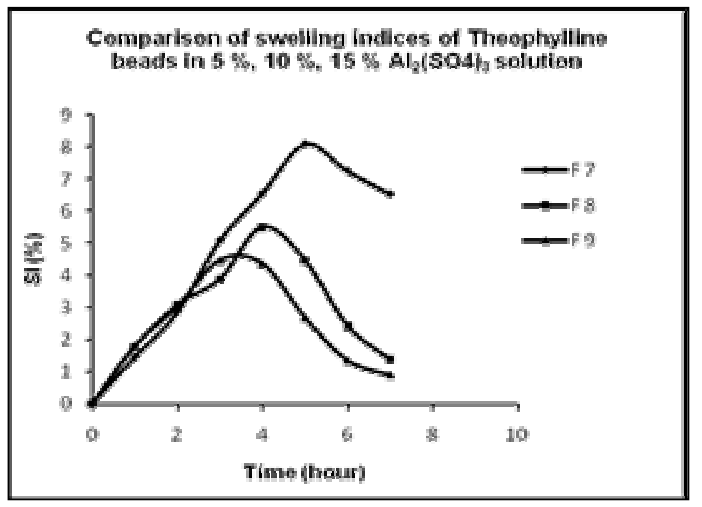

Figure 8. Comparison of swelling index of alginate based theophylline beads in $5 \%, 10 \% \& 15 \% \mathrm{Al}_{2}\left(\mathrm{SO}_{4}\right)_{3}$ solution 
Thus, in all cases 5\% electrolyte solution showed highest swelling compared to $10 \%$ and $15 \%$ solution. Thus, the swelling property decreased with increasing electrolyte concentration.

\section{In vitro dissolution study:}

Effect of various percentage of electrolyte solution on release pattern of theophylline from alginate beads. Depending on the amount of calcium present in the system, the inter-chain associations can be either temporary or permanent. With low levels of calcium, temporary associations are obtained, giving rise to highly viscous, thixotropic solutions. At higher calcium levels, precipitation or gelation results from permanent associations of the chains. ${ }^{20}$ Specifically, the G blocks (1-guluronic acid) are buckled while the $\mathrm{M}$ blocks (d-mannuronic acid) have a shape referred to as an extended ribbon. If 2 G-block regions are aligned side by side, a diamond shaped hole results. This hole has dimensions that are ideal for the cooperative binding of calcium ions. ${ }^{21}$

SEM photomicrographs in Figure 2 shows that F3 has highest cross linking as the percentage of $\mathrm{CaCl}_{2}$ is highest (15\%). F3 shows that the drug is strongly entrapped within the electrolyte and alginate structure. Here, the drug is visible as rod shapes and polymer surrounding them firmly. Thus, compared to F1 and F2, the SEM photomicrographs ensures the reason of low drug release from $\mathrm{F} 3$.

According to Figures 3 and 4 divalent $\mathrm{Ba}^{2+}$ cross links with alginate in such a way that the rod structures of theophylline can be easily visible. This phenomenon is attributed that surface erosion or initial disaggregation of beads has occurred. That's why the release of F7 is highest among these three formulations. SEM photomicrographs show that the trivalent $\mathrm{Al}^{3+}$ cross links with alginate in such a way that theophylline is strongly bounded within the cross links.

Surface morphology ensures that drug amount in surface is higher in F7 (Figure 5). Besides, F8 has less amount of drug visible in the surface. Comparatively the surface is also smoother. There are also some cracks through which drug can diffuse. For $\mathrm{F} 9$ the cross linking between alginate and $\mathrm{Al}^{3+}$ is highest because the amount of aluminium sulphate is highest $(15 \%)$. This attributes to the fact of releasing lowest amount of drug among these three formulations.

For most of the formulations the most appropriate model of drug release is Higuchi model. The Higuchi square root equation describes the release from systems where the solid drug is dispersed in an insoluble matrix, and the rate of drug release is related to the rate of drug diffusion. Formulations 1 and 2 follow Korsmeyer model (Fickian case I diffusion).

The dissolution data of F4 was plotted in accordance with the first-order equation, i.e., the logarithm of the percent remained as a function of time. It is evident from Table 2, that a linear relationship was obtained with ' $\mathrm{R}^{2}$, value close to unity and higher than ' $\mathrm{R}^{2}$, obtained from the zeroorder equation, showing that the release is an apparent first-order process. This indicates that the amount of drug released is dependent on the matrix drug load.

Table 2. Interpretation of R-squared values of different release profile of alginate based theophylline beads with various electrolytes

\begin{tabular}{lccccll}
\hline Formulation & \multicolumn{4}{c}{ Coefficients of correlation, $\mathrm{R}^{2}$} & \multirow{2}{*}{ Best fitted model } & Release Mechanism \\
\cline { 2 - 5 } Kinetic model & Zero order & First order & Higuchi & Korsmeyer & & \\
\hline 1 & 0.81 & 0.81 & 0.81 & 0.89 & Korsmeyer & Fickian (case I) diffusion \\
2 & 0.94 & 0.94 & 0.96 & 0.97 & Korsmeyer & Fickian (case I) diffusion \\
3 & 0.98 & 0.81 & 0.98 & 0.98 & Higuchi & Diffusion through pore formation \\
4 & 0.93 & 0.99 & 0.94 & 0.95 & First order kinetics & $\begin{array}{l}\text { Dependent on the concentration of the } \\
\text { dissolving species }\end{array}$ \\
5 & & & & & & Diffusion through pore formation \\
6 & 0.98 & 0.98 & 0.98 & 0.97 & Higuchi & Diffusion through pore formation \\
7 & 0.89 & 0.89 & 0.90 & 0.89 & Higuchi & Diffusion through pore formation \\
8 & 0.88 & 0.91 & 0.91 & 0.83 & Higuchi & Diffusion through pore formation \\
9 & 0.84 & 0.87 & 0.89 & 0.80 & Higuchi & Diffusion through pore formation \\
\hline
\end{tabular}


Effect of electrolytes on drug release rate. Here, the amount of alginate is same in all cases with varying concentration of calcium chloride, barium chloride and aluminium sulphate. In all the cases, with increasing electrolyte concentration the drug release rate is also decreased.

In $\mathrm{CaCl}_{2}$ series, $\mathrm{F} 1$ shows highest drug release (50\% at 8 hour) and F7 the lowest. The data reported in Figure 9, can be explained by considering the structure of the gel beads. Low $\mathrm{Ca}^{2+}$ concentration leads probably to a loose gel. As a consequence, the drug can be easily released from the beads, as the steric entanglements do not constitute a strong barrier. Further addition of $\mathrm{Ca}^{2+}$ gives a more structured gel and the drug is more retained inside the beads due to steric reason, since the existence of physical entanglements of crosslinked alginate- $\mathrm{Ca}^{2+}$ of lower dimensions controlling the drug diffusion flow within the beads. At high concentration of calcium chloride, strong and rigid gel is formed around the matrix and this strong gel does not allow the dissolution medium penetrate into the matrix at a high speed, resulting in a reduction in the release rate. This was proved with morphological study using SEM showing the dense feature of the formed beads. Same phenomena are observed in $\mathrm{BaCl}_{2}$ series and $\mathrm{Al}_{2}\left(\mathrm{SO}_{4}\right)_{3}$ series. ${ }^{12}$

Comparison among electrolyte solutions. The release behavior of alginate beads produced by ionic gelation with different cross linking agents depend upon the valency and size of the cations of respective cross linking agent.

$\mathrm{Ca}^{2+}$ and $\mathrm{Ba}^{2+}$ being divalent, form two dimensional bonding structures with sodium alginate. But, the $\mathrm{Ba}^{2+}$ has the largest size $\left(1.74 \mathrm{~A}^{0}\right)$ as compared to the other cations $\left(1.14 \mathrm{~A}^{0}\right.$ for $\mathrm{Ca}^{2+}$ and $0.68 \mathrm{~A}^{0}$ for $\mathrm{Al}^{3+}$ ), it is expected to form strong alginate microspheres and with smaller voids and low water uptake. In case of $\mathrm{Al}^{3+}$-alginate beads, the delay in release was due to the ability of $\mathrm{Al}^{3+}$ to form three dimensional bonding structure with the sodium alginate inside the beads. This three dimensional bonding results in extensive cross linking through the whole beads. As a result swelling of beads is delayed leading to slow disintegration. Simultaneously, when the electrolyte concentration is increased the release behavior also shows descending order. $^{11}$

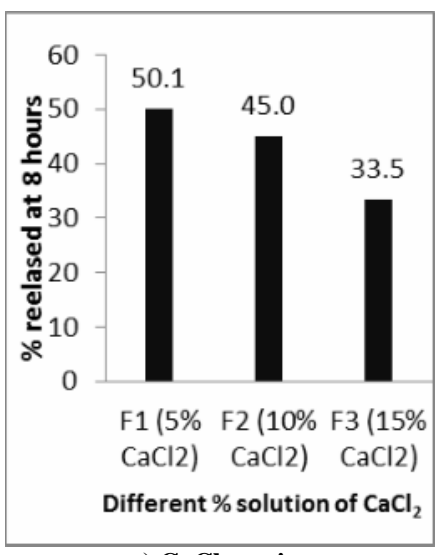

a) $\mathrm{CaCl}_{2}$ series

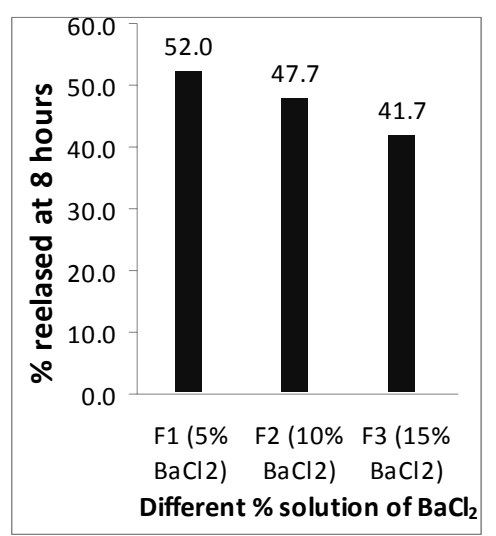

b) $\mathrm{BaCl}_{2}$ series

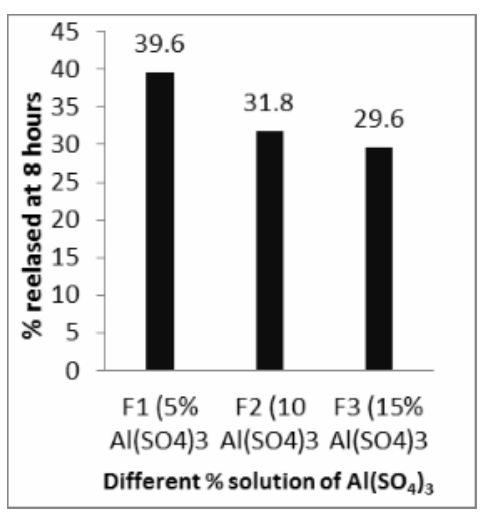

c) $\mathrm{Al}_{2}\left(\mathrm{SO}_{4}\right)_{3}$ series

Figure 9. Effect of different percent of electrolyte solutions on release pattern of Theophylline 
Effect of cationic charges on the release rate. The interaction between polyvalent cations like $\mathrm{Ca}^{2+}, \mathrm{Ba}^{2+}$ or $\mathrm{Al}^{3+}$ and negatively charged polymer like sodium alginate has been used in to prepare microsphere. ${ }^{22}$ In this study, the effect of using aluminum sulphate comparing to calcium chloride and barium chloride was investigated. The addition of cations was able to extend the drug release. This phenomenon is related to an in situ gel formation between the cations and the anionic polymer. The occurrence of in situ gel formation depends on the concentration of the cations. $^{23}$

The mechanism of gelation of sodium alginate with calcium was studied using rheological measurements. ${ }^{24}$ They reported that alginate solution containing a calcium concentration just below the gel point formed swollen aggregates of alginate molecules in the continuous phase. The gelation progress seemed to pass through a pre-gel state corresponding to clusters of alginate molecules before a continuous and infinite gel was formed.

According to Figure 9 formulations containing barium chloride and calcium chloride release drug to a higher extent compared to formulation containing aluminum sulphate. This difference in the release of theophylline of different cations can be explained by the difference in binding strength of calcium, barium and aluminum ions to alginate, since aluminum ions have an extra positive charge compared to divalent calcium and barium ions thus each molecule of aluminum is able to bind to one more alginate molecule. Because of this, aluminum sulphate was capable of forming a gel more quickly and which did not allow the dissolution medium to quickly enter the beads. Thus the dissolution rate compared to the formulation containing the same number of moles of calcium chloride and barium chloride was lower.

\section{CONCLUSION}

Large spherical theophylline loaded alginate beads were prepared successfully by ionotropic gelation technique. Theophylline release from these beads was slow and extended over longer period of time and was found to depend on the type and amount of the polyvalent cationic cross linking agent used. Comparative study of six formulations of theophylline-alginate with $\mathrm{CaCl}_{2}, \mathrm{BaCl}_{2}$ and $\mathrm{Al}_{2}\left(\mathrm{SO}_{4}\right)_{3}$ shows that $\mathrm{BaCl}_{2}$ containing formulations exhibit the highest release of drug. Secondly comes $\mathrm{CaCl}_{2}$ and then $\mathrm{Al}_{2}\left(\mathrm{SO}_{4}\right)_{3}$. In conclusion, theophylline is capable of being entrapped as a bead formulation, with suitable properties and release profile. These beads are thus suitable for oral control release formulation of theophylline.

\section{ACKNOLEDGEMENTS}

The authors are grateful to Eskayef Pharmaceuticals Ltd, Bangladesh for generously providing the sample of theophylline anhydrous. The authors also thank Bangladesh Council of Scientific and Industrial Research (BCSIR) laboratories, Dhaka for Scanning Electron Microscopic (SEM) studies.

\section{REFERENCES}

1. Shilpa, A., Agrawal, S.S. and Rao. A.R. 2003. Controlled delivery of drugs from alginate matrix. J. Macromol. Sci-Polym. Rev. 43, 187-221.

2. Draget, K.I., Skjak-Braek, G. and Smidsrod, O. 1997. Alginate based new materials. Int. J. Biol. Macromol. 21, 47-55.

3. Tomida, H., Mizuo, C., Nakamura, C. and Kiryu, S. 1993. Imipramine release from $\mathrm{Ca}$ - alginate gel beads. Chem. Pharm. Bull. (Tokyo). 41, 1475-1477.

4. Lim, L.Y. and Wan, L.S.C. 1997. Propranolol hydrochloride binding in calcium alginate beads. Drug Dev. Ind. Pharm. 23, 973-980.

5. Batchelor, H.K., Banning, D., Dettmar, P.W., Hampson, F.C., Jolliffe, I.J. and Craig, D.Q. M. 2002. An in-vitro mucosal model for the prediction of the bioadhesion of alginate solutions to the oesophagus. Int. J. Pharm. 238, 123132.

6. Blandino, A., Macias, M. and Cantero, D. 2000. Glucose oxidase release from calcium alginate gel capsules. Enzyme Microb. Technol. 27, 319-324.

7. Bodmeier, R. and Paeratakul, O. 1989. Spherical agglomerates of water-insoluble drugs. J. Pharm. Sci. 78, 964967.

8. Bodmeier, R. and Wang, J. 1993. Microencapsula-tion of drugs with aqueous colloidal polymer dispersions. $J$. Pharm. Sci. 82, 191-194. 
9. Zhiling, Y., Schwartzt, J.B. and Sugita, E.T. 1996. Theophylline controlled-release formulations: in vivo-in vitro correlations. Biopharm. drug dispos. 17, 259-272.

10. Fagerstroem, P.O., Mellastrand, T. and Svedmyr, N. 1981. Absorption of theophylline from conventional and sustained-release tablets. Int. J. Clin. Pharmacol. Ther. Toxicol. 19, 131-138.

11. Das, M.K. and Senapati, P.C. 2008. Furosemide loaded Alginate Microspheres prepared by Ionic cross-linking technique: Morphology and Release Characteristics. Indian J. Pharm. Sci. 70, 77-84.

12. El-Zatahry, A.A., Soliman, E.A., Hassan, E.A. and Eldin, M.S.M. 2006. Preparation and in vitro release of Theophylline loaded sodium alginate microspheres. ASTFScientific Research Outlook Conference. p.155, Category [T6-4] Basic sciences.

13. Yeole, P.G., Galgatee, U.C., Babla, I.B. and Nakhat, P.D. 2006. Design and evaluation of Xanthan gum based sustained release matrix tablets of Diclofenac Na. Indian J. Pharm. Sci. 68, 185-189.

14. Donbrow, M. and Samuelov, Y. 1980. Zero order drug delivery from double-layered porous films: release rate profiles from ethylcellulose, hydroxypropylcellulose and polyethylene glycol mixtures. J. Pharm. Pharmacol. 32, 463470.

15. Higuchi, T. 1961. Rate of release of medicaments from ointment bases containing drugs in suspension. J. Pharm. Sci. 50, 874-875.

16. Higuchi T. 1963. Mechanism of sustained-action medication: theoretical analysis of rate of release of solid drugs dispersed in solid matrices. J. Pharm. Sci. 52, 1145-1149.
17. Merchant, H. A., Shoaib, H. M., Tazeen, J., Yousuf, R.I. 2006. Once-Daily tablet formulation and in vitro release evaluation of Cefpodoxime using Hydroxypropyl Methylcellulose: A Technical note. AAPS Pharm. Sci. Tech. 7(3), Article 78.

18. Korsmeyer, R.W., Gurny, R., Doelker, E.M., Buri, P. and Peppas, N.A. 1983. Mechanism of solute release from porous hydrophilic polymers. Int. J. Pharm. 15, 25-35.

19. Falamarzian, M. and Varshosaz, J. 1998. The effect of structural changes on swelling kinetics of polybasic/ hydrophobic pH-sensitive hydrogels. Drug Dev. Ind. Pharm. 24, 667-669.

20. Algin, C.K. In: Whistler, R.L. and BeMiller, J.N., 1992. eds. Industrial Gums. 3rd ed. New York, NY: Academic Press.

21. Braccini, I. and Perez, S. 2001. Molecular basis of $\mathrm{Ca}^{2+}$ induced gelation in alginates and pectins: the egg-box model revisited. Biomacromolecules. 2, 1089-1096.

22. Lim, L.Y. and Wan, L.S.C. 1997. Propranolol hydrochloride binding in calcium alginate beads. Drug Develop. Indus. Pharm. 23, 973-980.

23. Bodmeier, R., Chen, H. and Paeratakul, O. 1989. A novel approach to the oral delivery of micro- or nanoparticles. Pharm. Res. 6, 413-417.

24. Vauthier, C., Rajaonarivony, M., Couarraze, G., Couvreur, P. and Puisieux, F. 1994. The mechanism of gelation of sodium alginate: rheological measurement. European $J$. Pharm. Biopharmaceut. 40, 218-227. 